EESTI NSV TEADUSTE AKADEEMIA TOIMETISED. IX KÖIDE FOOSIKALIS-MATEMAATILISTE JA TEHNILISTE TEADUSTE SEERIA, 1960, NR. 3

ИЗВЕСТИЯ АКАДЕМИИ НАУК ЭСТОНСКОП ССР. ТОМ IX СЕРИЯ ФИЗИКО-МАТЕМАТИЧЕСКИХ И ТЕХНИЧЕСКИХ НАУК. 1960, № 3

\title{
PLUMATALINIA - НОВЫЙ РОД ОТРЯДА STROMATOPOROIDEA ИЗ ВЕРХНЕГО ОРДОВИКА ЭСТОНСКОЙ ССР
}

\section{HECTOP}

В пиргуском горизонте $\left(\mathrm{F}_{1} \mathrm{c}\right)$ старой каменоломни близ деревни Нийби Хаапсалуского района и в биогермах, расположенных поблизости, автор настоящей статьи нашел своеобразные ценостеумы ранее не описанного вида строматопор, относящегося, очевидно, к семейству Labechiidae Nicholson, 1879. Но поскольку найденные формє четко отличаются от всех известных родов семейства Labechiidae, автор делает заключение об их принадлежности к новому роду - Plumatalinia gen. n.

Если из ордовика Северной Америки и разных районов Азии известна сравнительно богатая фауна строматопор, то из ордовика Европы и, в частности, из Балтоскандии сведения о них пока еще очень скудны. Не считая единственного определения вида Stromatocérium canadense Nicholson из ордовика Шотландии [6] и находки Холтедалем [3] Stromatopora sp. с острова Смэлен (Smölen, Норвегия), наиболее полные данные имеются по Эстонии. Из ордовика Эстонии, кроме Plumatalinia, известны еще роды Stromatocerium Hall, 1847 , из оандуского ( $\left.\mathrm{D}_{\mathrm{III}}\right)$ и вормсиского $\left(\mathrm{F}_{\mathrm{I}} \mathrm{b}\right)$ горизонтов и Clathrodictyon Nicholson et Murie, 1878, из вормсиского и пиргуского горизонтов. По данным Рябинина [ $\left.{ }^{1}\right]$, из вормсиского и пиргуского горизонтов известен также род Stromatopora Goldfuss, 1826.

\section{СЕМЕЙТВО LABECHIIDAE NICHOLSON, 1879}

\section{Род Plumatalinia gen. n.}

Т и по в ой в и д: Plumatalinia ferax sp. n. - верхний ордовик, пиргуский горизонт $\left(\mathrm{F}_{1} \mathrm{c}\right)$; Эстонская $\mathrm{CCP}$, Хаапсалуский район, деревня Нийби.

Д и а гно з. Массивный ценостеум с базальной эпитекой. На верхней поверхности имеются круглые углубления (воронки), соответствующие выходу колонн на поверхность ценостеума. Внутри последнего наблюдаются радиальные круглые колонны, состоящие из неправильной тонкосетчатой ткани. Между колоннами имеется пузырчатая ткань. Стенки пузырьков поперечноволокнистые. Зоидальные трубки и астроризы отсутствуют.

Систематическое положение рода и сравнение. Bсе пузырчато-тканистые строматопоры, образующие основную часть 
ордовикских строматопор, относятся, согласно Никольсону [ $\left.{ }^{6}\right]$, Яворскому $\left.{ }^{2}\right]$ и др., к семейству Labechiidae Nicholson, 1879. Другие авторы, например Раймонд [7], Кюнн [4] и Лекомпт [5], распределяют пузырчатотканистые строматопоры между семействами Labechiidae Nicholson, 1879 , к которому они относят массивные и инкрустирующие формы, н Aulaceridae Kühn, 1927 (Beatricidae Raymond, 1932), в которое они включают цилиндрические или ветвящиеся колонии с широким осевым каналом, имеющим сильно выпуклые табулы (перегородки).

Мы придерживаемся последней точки зрения, как вполне обоснованной, и относим Plumatalinia к семейству Labechiidae в смысле Кюна.

От другого представителя семейства Labechiidae ордовика Эстонии рода Stromatocerium - Plumatalinia отличается четко, так как она имеет толстые колонны тонкосетчатой ткани вместо вертикальных пластинок Stromatocerium.

C первого взгляда самым близким к Plumatalinia кажется род Pseudolabechia Yabe et Sugiyama, 1930, известный из ордовикских, силурийских и девонских отложений, также имеющий сложные вертикальные колонны и пузырчатую ткань. Но от Plumatalinia последний легко отличается тем, что у Pseudolabechia колонны снабжены боковыми ветвями, направленными вверх к бокам, и тем, что колонны ее образуют на поверхности ценостеума бугорки, а не воронки.

Вертикальные колонны, но более компактного строения, имеются также у девонского рода Stylodictyon Nicholson et Murie, 1878, но у последнего нет пузырчатой ткани и относится он к семейству Actinostromatidae Nicholson, 1886.

Род Plumatalinia занимает среди родов семейства Labechidae несколько особое место, поскольку у него стенки пузырчатой ткани поперечноволокнистые, в то время как у других представителей семейства они компактные или зернистые. Но пока еще не ясно, какую роль в этом может играть перекристаллизация.

\section{Plumatalinia ferax sp. n.}

ТАБЛ. І и ІІ.

\section{Гол о тип: Со 3001; Геологический музей АН Әстонской ССР.}

Типовой горизонт и типовое местонахождение. Верхний ордовик, пиргуский горизонт $\left(\mathrm{F}_{\mathrm{I}} \mathrm{c}\right)$; Хаапсалуский район, Эстонская ССР, деревня Нййби.

Д и аг но 3. Ценостеум обычно полусферический. Базальная эпитека имеется. Пузырьки пузырчатой ткани очень длинные и невысокие. Вертикальные колонны круглые, развиты хорошо, расположены неравномерно. Тонкосетчатая ткань очень неправильная, тонкая и густая. Колонны не имеют четких очертаний, тонкосетчатая ткань местами распространяется от колонн в горизонтальном направлении между пузырьками, образуя неправильные пятна или широкие полосы.

Опи с ани е. Почти целый неправильный полусферический ценостеум голотипа с вогнутым основанием. Размеры ценостеума 16 Х $\times 14 \times 6$ см. На поверхности имеются неглубокие, едва заметные круглые воронки, глубина которых равна приблизительно $0,2-0,4$ мм, ширина - 0,4-0,5 мм. Воронки, вероятно, обозначают места выхода колонн на поверхность ценостеума. Расстояние между воронками $1-1,5$ мм. На нижней поверхности слабая эпитека. 

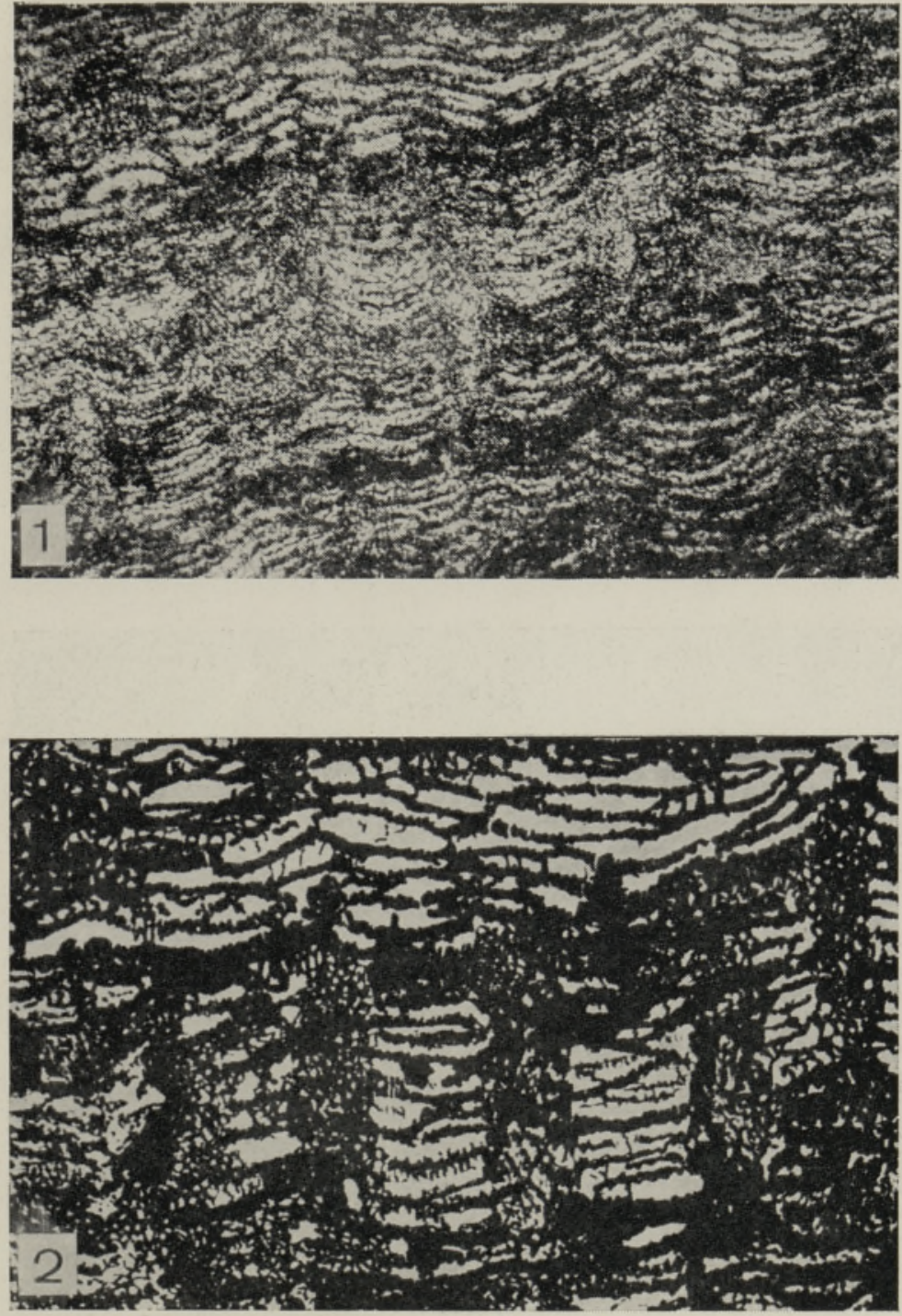

1 - Plumatalinia ferax sp. n.; Сo 3001 (голотип); Эстонская ССР, Нийби; верхний ордовик, пиргуский горизонт $\left(\mathrm{F}_{\mathrm{I}} \mathrm{c}\right)$; радиальный шлиф, $\times 10$.

2 - то же, схематический рисунок, $\times 15$. 

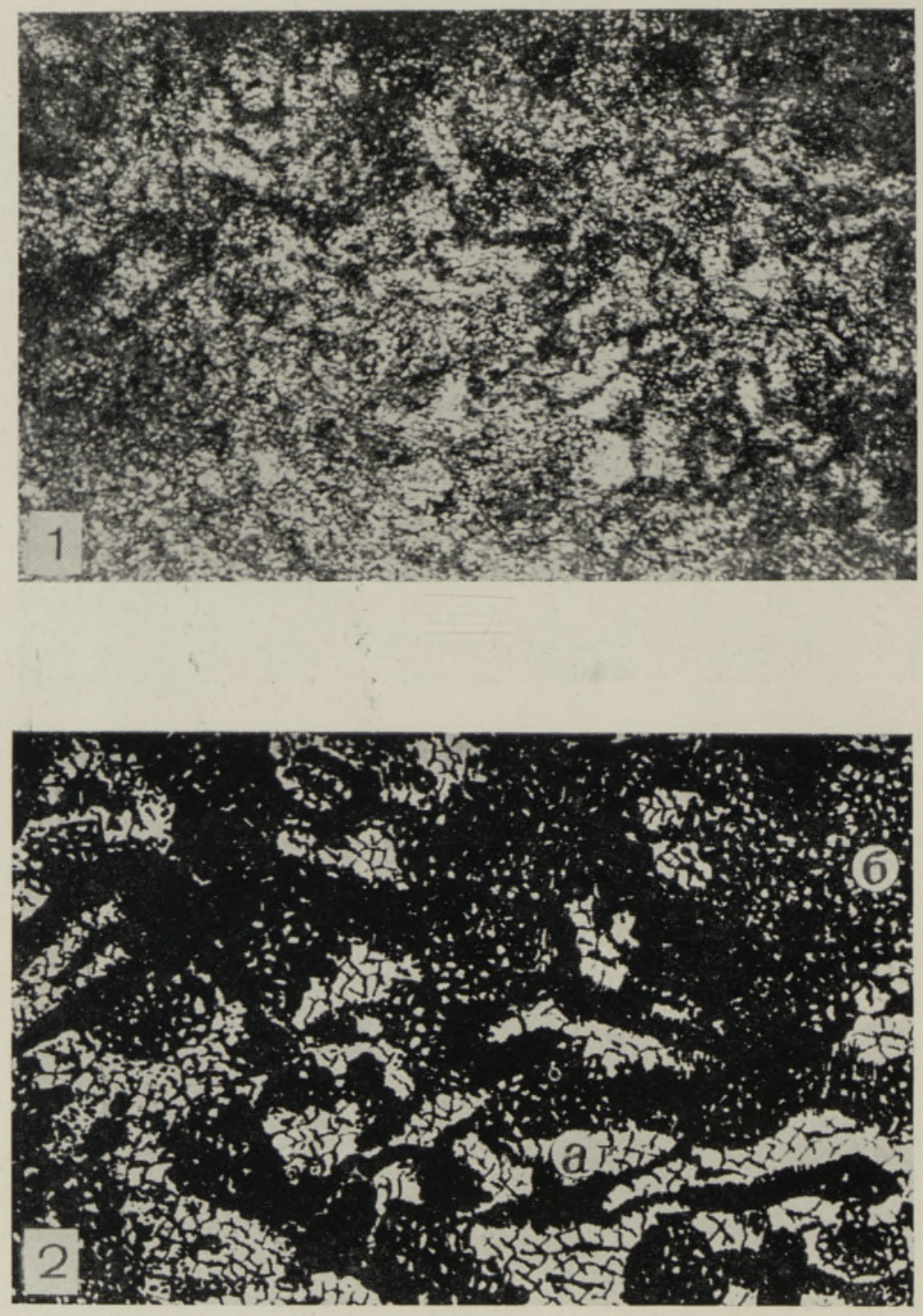

1 - Plumatalinia ferax sp. n.; Co 3001 (голотип); Эстонская ССР, Нийби; верхний ордовик, пиргуский горизонт $\left(\mathrm{F}_{\mathrm{I}} \mathrm{c}\right)$; тангенциальный шлиф, $\times 10$.

2 - то же, схематический рисунок, $\times 15: a$ - выше буквы сечение вертикальной колонны; б - межколонная

тонкосетчатая ткань, 
Радиальный шлиф. Пузырьки пузырчатой ткани сравнтельно длинные и низкие: их высота 0,15 мм, длина $1-2$ мм. Нa 1 мм (в вертикальном направленин) приходится в среднем 6 пузырьков. Пузырьки слабо выпуклые, стенки их иногда проходят почти параллельно друг другу, напоминая волнистые лямины.

В радиальном направлении через ценостеум проникают круглые колонны очень различной длины (от 1,5 до 7-8 мм). Диаметр колонн $0,4-0,5$ мм, расстояние друг от друга очень изменчиво, в среднем 1,0 1,5 мм. Состоят они из густой неправильной тонкосетчатой ткани и не имеют четкого очертания. Наоборот, тонкосетчатая ткань распространяется от них и в горизонтальном направлении далеко между пузырьками. Местами, где колонны расположены чаще, тонкосетчатая ткань почти полностью заменяет пузырчатую, так что получаются горизонтальные полосы или пятна очень тонкой и неясной структуры.

Толщина стенок пузырчатой ткани в среднем 0,066 мм. Стенки не компактные, а поперечноволокнистые и, по-видимому, пронизаны тончайшими вертикальными каналами.

В тангенциальном шлифе видны круглые сечения вертикальных колонн с тонкосетчатой тканью. Кроме того, видны кривые линии, обозначающие сечения пузырьков. Межколонная тонкосетчатая ткань наблюдается в виде пятень неправильной формы. форм.

С р а в н ен и е. Вид четко отличается от всех известных до сих пор

Р аспространение и м те ри ал. Все 6 экземпляров вида собраны в пиргуском горизонте из старой каменоломни и биогермов вблизи деревни Нийби.

Эстонская ССР. Верхний ордовик.

\section{Л И Т Е Р А Т У Р А}

1. В. Н. Р ябин и н, Строматопороидеи Эстонской ССР, Тр. ВНИГРИ, нов. сер., вып. $43,1951$.

2. В. И. Я в о р с к и й, Stromatoporoidea Советского Союза, ч. 1, Тр. ВСЕГЕИ, нов. сер., т. 8, 1955.

3. O. Holtedahl, Fossiler fra Smölen, Norges Geol. Untersökelse, No. 69, 1914.

4. O. K ü h n, Hydrozoa, In O. H. S c h i n d ew olf, Handbuch der Paläozoologie, B. 2A, Berlin, 1939.

5. M. L e c o m p te, Stromatoporoidea, In Treatise on Invertebrate Paleontology, Part F, Coelenterata, Geological Society of America and University of Kansas Press, 1956.

6. H. A. Nicholson. A Monograph of the British Stromatoporoids, Palaentographical Society, London, 1886-1892.

7. P. E. R a y m on d, Notes on Invertebrate Fossils with Description of New Species, Bull Mus. Comp. Zool. Harvard College, Vol. LV, No. 6; Geol. Ser., Vol. IX, No. $6,1931$. 


\title{
PLUMATALINIA - UUS STROMATOPOROIDEA PEREKOND EESTI OLEM-ORDOVIITSIUMIST
}

\author{
H. Nestor
}

Resümee

Artiklis kirjeldatakse sugukonda Labechiidae Nicholson, 1879 kuuluvat uut stromatopooride perekonda Plumatalinia gen. n., mis esineb Eestis pirgu lademes $\left(\mathrm{F}_{\mathrm{I}} \mathrm{c}\right)$.

Perekonna diagnoos on järgmine:

Basaalse epiteekaga massiivne tsönosteum ümmarguste lehterjate süvenditega pealmisel pinnal. Tsönosteumi sisemuses esinevad radiaalsed ümmargused sambad, mis koosnevad korrapäratust peenvõrkjast koest. Sammastevahelist ruumi täidab ristkiuliste seintega pōisjas kude. Astroriisid ja zoöidaaltorukesed puuduvad.

Plumatalinia sarnaneb perekonnaga Pseudolabechia Yabe et Sugiyama, kuid tema sammastel puuduvad külgharud ja tsönosteumi pind ei ole kaetud nåsadega.

Perekonnast on teada üks liik - Plumatalinia ferax gen. et sp. n.

\author{
Eesti NSV Teaduste Akadeemia \\ Geoloogia Instituut
}

Saabus toimetusse

24. III 1960

\section{PLUMATALINIA - A NEW GENUS OF STROMATOPOROIDEA FROM THE UPPER ORDOVICIAN OF THE ESTONIAN S.S.R.}

\section{H. Nestor \\ Summary}

In the present article a new stromatoporoid genus Plumatalinia belonging to the family Labechiidae Nicholson, 1879 , occurring in the Pirgu stage $\left(F_{1} c\right)$ of the Estonian S.S.R., is described.

The diagnosis of the genus is the following:

Massive coenosteum with basal epitheca. The upper surface exhibits numerous round craters. Inside the coenosteum round columns are observed. They are composed of a thin irregular network-tissue. The intercolumnar room is filled with vesicular tissue. The walls of the vesicles are transversely fibrous. Astrorhizae and zooöidal tubes are absent.

Plumatalinia is similar to the genus Pseudolabechia Yabe et Sugiyana, but its columns lack lateral branches and the surface has no monticules.

$\mathrm{Up}_{\mathrm{p}}$ to the present only one species - Plumatalinia ferax gen. et sp. n. - is known.

Academy of Sciences of the Estonian S.S.R.,

Received Institute of Geology 